\begin{tabular}{lcl}
\hline Bentham OPEN & The Open PSychology Journal \\
CrossMark & Content list available at: www.benthamopen.com/TOPSYJ/ & DOI: $10.2174 / 1874350101710010061$ \\
\hline
\end{tabular}

RESEARCH ARTICLE

\title{
Self-Focus and Cardiovascular Effects of Stressor Anticipation and Active Coping: The Moderating Influence of Trait Social Anxiety
}

\author{
Margit Gramer ${ }^{*}$ and Stephanie Frei \\ Department of Psychology, University of Graz, Graz, Austria
}

Received: January 17, 2017

Revised: February 21, 2017

Accepted: April 19, 2017

\begin{abstract}
:
Background:

Self-focused attention has been found to facilitate task engagement and cardiac activity in active performance situations. According to theories on self-awareness this facilitating effect might be confined to individuals with favorable outcome expectancies, though.
\end{abstract}

\section{Objective:}

To provide information on this issue, the present study evaluated the moderating influence of trait social anxiety, a dispositional indicator of impaired confidence. In extension of prior research, effects of enhanced self-awareness were assessed during both anticipation and performance of an active social stressor.

\section{Method:}

Sixty normotensive female students characterized as either high or low in trait social anxiety engaged in an evaluative speaking task either in the context of high or low self-awareness.

\section{Results:}

The moderating influence of social anxiety was found to vary with type of demand. During passive stressor anticipation, self-focus augmented distress-related vascular reactivity in high but not in low socially anxious individuals. During speech preparation selffocus was found to facilitate task engagement and cardiac reactivity in low socially anxious individuals, whereas high anxious showed some withdrawal. Greater self-awareness during speech performance elicited cardiac increases in both social anxiety groups. However, among high anxious individuals this sustained engagement was accompanied by increased negative affect and negative self-evaluations.

\section{Conclusion:}

These findings seem to suggest that only in high socially anxious individuals heightened self-awareness may contribute to dysfunctional cardiovascular and psychological processes.

Keywords: Self-focused attention, Social anxiety, Cognitive appraisals, Cardiovascular reactivity, Stressor anticipation, Active coping.

\section{INTRODUCTION}

It is well established that the type of behavioral demand exerts a substantial influence on the intensity and patterning of cardiovascular responses. In particular, Obrist's [1] typology of active vs. passive coping has been found to elicit distinct cardiovascular adjustments. Active coping tasks provide the opportunity to exert control over outcomes in

\footnotetext{
* Address correspondence to this author at the Department of Psychology, University of Graz, Universitätsplatz 2, A-8010 Graz, Austria, Tel: +43 316380 5130; Fax: +43 316380 9808; E-mail margit.gramer@uni-graz.at
} 
accordance with abilities and efforts. They were found to elicit large beta-adrenergically mediated increases in cardiac activity with systolic blood pressure (SBP) and heart rate (HR) being most reliably affected [2, 3]. Simultaneous effects in diastolic blood pressure (DBP) have also been observed but are considered to be less likely [4]. The myocardial effects of active coping have been observed in appetitive [5, 6] and aversive conditions [7] and are considered to reflect energy mobilization or effort to facilitate coping with situational demands rather than affective arousal [1, 4]. Cardiovascular responses accompanying the passive tolerance or endurance of a stressor were found to be mediated by alpha-adrenergic pathways, indicated by enhanced vascular reactivity, i.e., increases in blood pressure (BP) - in particular DBP - but not HR [1,3].

Research on the specific determinants of effort expenditure in active performance situations was greatly stimulated by Wright's [4] integration of Obrist's [1] active coping approach with Brehm's theory of motivational intensity [8]. This integrative analysis assumes that effort expenditure in active performance situations corresponds to experienced task demand as long as success is perceived as possible and worthwhile. In situations exceeding perceived coping ability attenuated cardiac activity might be observed. Withdrawal of effort in difficult task situations may be moderated by success importance (or the level of potential motivation), though. When importance is very high (e.g., strong aversive consequences can be avoided or high rewards gained) individuals may keep up effort expenditure and cardiac activity (SBP, HR) also in very difficult, though not in impossible performance conditions [2]. Recently, self-focused attention - the process of directing attention towards internal self-relevant stimuli - [9] has been introduced as another determinant of success importance. Several studies observed individuals exposed to high self-focus to expend more effort in difficult cognitive tasks compared to those low in self-focus [10,11]. Thus, self-focus seems to make the task important enough to justify high effort investment [11]. According to theories on self-awareness [12, 13], self-focused attention initiates a self-standard comparison and - in case of discrepancies between actual self and salient standard accelerates activity aimed at discrepancy reduction. These facilitating effects on goal-directed behavior are only expected when outcome expectancies are favorable, though. In doubtful individuals, self-focus should enhance the tendency to disengage from the goal behaviorally or mentally, unless situational constraints prevent withdrawal. In situations with high constraints (i.e., performance settings) doubtful individuals may continue to confront the goal. However, this effort might be less organized and should be accompanied by a rise in negative feelings and sustained self-doubts [13].

To date, cardiovascular research on self-focused attention has largely neglected vulnerable populations (i.e., individuals with impaired self-efficacy). One study considered the moderating influence of trait social anxiety [14] but observed no differential effects in cardiovascular (HR) activity. This may partly be a result of the utilized stressor, a cognitive task with evaluative features. There is some evidence that reduced confidence of socially anxious individuals might be confined to social stressors, whereas cognitive tasks seem to elicit comparable success expectations in high and low socially anxious individuals, even in the presence of an evaluative audience [15]. Research on the cardiovascular effects of trait social anxiety in social stress conditions (i.e., public speaking tasks) has repeatedly observed differential cardiovascular activity. These effects were inconsistent, though. Some studies found socially anxious individuals to exhibit heightened cardiac activity [16 - 20], others observed reduced reactivity and withdrawal of effort [21 - 23], particularly in highly demanding social tasks. In terms of the integrative effort analysis these discrepant results might indicate that socially anxious individuals exhibit heightened cardiac activity as long as both groups view success as possible (due to higher perceived demand), but withdraw effort in situations that severely threaten perceived coping ability. In this respect, it is of note that evaluative speaking tasks include features that might be potentially self-focusing. Participants are usually required to perform in front of a video camera or an audience. Cameras and audiences make individuals more aware of themselves [24]. However, self-focus was neither assessed nor manipulated in these studies. A major aim of the present study was to provide empirical data on this issue. According to cognitive models of social anxiety [25] and experimental evidence [14, 26], detrimental effects of self-focused attention might be confined to situations with potential evaluative threat. The present study therefore evaluated whether adding an explicitly self-focusing feature (watching oneself in real-time on a monitor) to a basic social threat paradigm (videotaped speech without seeing oneself) would differentially influence task engagement and cardiac activity in high and low socially anxious individuals.

Drawing from theoretical contributions on self-awareness $[12,13]$ and available findings on the cardiovascular effects of induced self-focus [10,11], enhanced compared to low self-focus should facilitate task engagement and related cardiac activity (i.e., elevations in SBP and/or HR) in low socially anxious individuals. In high anxious individuals, increased self-doubts under high self-awareness [13] may provoke or intensify withdrawal tendencies 
indicated by attenuated cardiac activity [21, 22]. It cannot be excluded, though, that greater success importance under high self-focus and the constraints of the structured speech task may lead socially anxious individuals to persist despite low confidence. Thus, enhanced self-focus might go along with heightened cardiac activity in both groups. In high socially anxious individuals sustained task engagement could be accompanied by heightened distress and dysfunctional cognitions, though [13].

In addition to cardiovascular effects during stressor exposure, the present study also evaluated potential effects of self-awareness during stressor anticipation. To date, research on self-focused attention has neglected this period of prolonged stressor exposure. In contrast to active stressor performance, stressor anticipation was found to be characterized by vascular activity (i.e., elevations in BP but not HR [27]). This response pattern is considered to reflect coping with negative affect [28] and/or dysfunctional perseverative cognitions (i.e., anticipatory worrying, see [29]). Maladaptive anticipatory processing (i.e., thoughts about ways in which to avoid the situation, negative self-evaluative thoughts, catastrophizing) constitutes a core cognitive characteristic of trait social anxiety [30, 31], and there is some evidence that engaging in anticipatory processing may have more detrimental psychological effects in high compared to low socially anxious individuals [32]. Furthermore, self-focus is considered to increase access to negative thoughts [33]. Accordingly, high socially anxious individuals were expected to exhibit stronger BP elevations during stressor anticipation, and this effect might be amplified under enhanced self-focus.

\section{METHOD}

\section{Participants}

Sixty normotensive female students completed this study in exchange for course credits and/or information on their blood pressure. Participants were recruited using the university's web-based experiment scheduling system. Exclusion criteria included a BMI > 29, a hypertensive status, pregnancy, and use of medications that may influence CVR or may indicate psychological disorders. The Social Anxiety Scale (SAP) developed by Lück [34] was used for selection. Participants were assigned to social anxiety groups on the basis of a median split of the final distribution of test scores $(M=11.43, S D=5.12)$. The sample mean was comparable to means observed by Lück and cutoff criteria employed in previous research noting cardiovascular and psychological effects of social anxiety $[17,18]$. The mean score for high socially anxious individuals was $15.53(S D=3.43)$, the mean score for low socially anxious individuals was $7.33(S D=$ $2.60), p<0.0001$. High and low socially anxious participants were matched across experimental conditions. Half of each social anxiety group performed the task under high self-focus, the other half performed it under low self-focus. The mean anxiety score for high self-focus was $11.47(S D=5.39)$, the mean score for low self-focus was $11.40(S D=$ 4.92). Participants ranged in age from 18 to 34 years $(M=22.42 ; S D=2.98)$, their mean BMI was $21.65 \mathrm{~kg} / \mathrm{m}^{2}(S D=$ $2.51)$, with no differences between experimental groups ( $p$ 's $>0.11)$.

\section{Experimental Tasks and Procedure}

On arrival participants were given written information concerning the experiment. The study was introduced as an assessment of cardiovascular activity under rest and demand. After informed consent was obtained, the experimental session was initiated by a 10-min rest period. The experimenter remained unobtrusively seated somewhat behind the participant. Then a 5-min stressor anticipation period followed. Participants were informed that they would have to give a 5-min speech in front of a video camera and that they would have $5 \mathrm{~min}$ to prepare their speech. They were not informed on the topic of the speech at that time, though. In preparation of the upcoming recording, the experimenter placed a digital camera before the participant. In the condition with enhanced self-focus the participants could see themselves on a monitor placed to the left of the camera. In the condition without enhanced self-focus the monitor remained black. This self-focus procedure was found to enhance self-awareness and the willingness to mobilize energy in an evaluative cognitive performance situation [10]. To standardize participants' expectations during anticipation a countdown with 1-min intervals presented by an audiotape was utilized [27]. Then participants were exposed to the task combination Speech Preparation/Speech Performance. They were required to prepare and deliver a speech in which they applied for a position in their academic field. A 5-min preparation period led directly into a 5-min speech talking period. If subjects stopped speaking before the end of the task period, they were prompted with standard questions to continue speaking. Participants were informed that their video-taped speeches would be evaluated according to the quality and effectiveness of arguments, poise and self-confidence of their presentation. A final 10-min post-stress period ended physiological recordings. During this period the camera was turned off. 


\section{Measures}

\section{Cardiovascular assessments}

SBP, DBP, and HR were assessed with the TM-2430 (BOSCH \& SOHN GmbH \& Co. KG, Germany) oscillometric monitoring system. This device is equipped to detect artifact caused by movement or poor cuff placement and fulfills the criteria of the British Hypertension Society protocol [35]. Readings of BP and HR were taken at 5-min intervals during initial rest and recovery periods (that is, immediately at rest or recovery onset, 5 min later and at the end of these periods). During stressor anticipation, speech preparation/speech performance readings were taken 1 and 4 min after task period onset.

\section{Psychological Assessments}

Trait social anxiety was assessed with the Social Anxiety Scale (SAP) developed by Lück [34]. This device involves a wide range of social situations. As indicated by Vormbrock and Neuser [36], the SAP shows substantial correlations with the "Fear of Negative Evaluation "scale (FNE) and the "Social Avoidance and Distress" scale (SAD) by Watson \& Friend [37]. Alpha in the present study was 0.82 .

\section{Emotional States and Appraisals}

The Positive and Negative Affect Schedule (PANAS) developed by Watson, Clark, and Telegen [38] was utilized to assess affective states on completion of rest and task periods. This 20 -item measure uses five-point scales ranging from 1 (very slightly) to 5 (extremely). Alphas in the present study ranged from 0.91 (PA) to 0.87 (NA).

Drawing from Tomaka, Blascovich, Kelsey, and Leitten [39], two seven-point Likert-type scales $(1=$ not at all, $7=$ very) assessed the threatening quality of the upcoming task (demand appraisal) and perceived coping ability (resource appraisal). Additionally, a third seven-point scale assessed expected task difficulty. Appraisal ratings were presented after task instruction but before task onset.

The Modified Perception of Speech Performance (MPSP) questionnaire by Cody and Teachman [40] was utilized as a subjective performance measure. This 12-item scale asks participants to appraise their performance with regard to specific (e.g., kept eye contact) and global aspects (e.g., was a good public speaker) of their speech on a 5-point rating scale. Alpha in the present study was 0.92. Additionally, number of received prompts was counted.

The Focus of Attention Questionnaire (FAQ) by Woody [41] was used to assess content of attention during the social stressor. This measure is composed of two 5-item scales: $\mathrm{FAQ}_{\text {self }}$ (e.g., I was focusing on my internal bodily reactions) and $\mathrm{FAQ}_{\text {other }}$ (e.g., I was focusing on what the other person was saying or doing). Agreement with each statement was rated on five-point Likert-type scales. Alphas in the present sample were $0.72\left(F^{2} Q_{\text {self }}\right)$ and 0.68 $\left(\mathrm{FAQ}_{\text {other }}\right)$.

\section{Data Reduction and Statistical Analyses}

The averages of the cardiovascular values assessed during the last $5 \mathrm{~min}$ of the initial rest period (measurements 2 and 3) constituted baseline values for SBP, DBP, and HR. To evaluate the differential impact of social anxiety and induced self-focus on cardiovascular responses to stressor anticipation, change $(\Delta)$ scores computed as differences between mean task (anticipation) levels and initial resting (baseline) levels were subjected to 2 (social anxiety) x 2 (selffocus) $\mathrm{AN}(\mathrm{C}) \mathrm{OVAs}$ controlling for baseline levels in case of significant correlations with delta scores. To minimize carry over effects of the anticipatory period and to evaluate the specific effects of the active stressor, cardiovascular reactivity to speech preparation/speech performance was defined as elevations from pretask anticipation levels. Change $(\Delta)$ scores computed as difference between mean task levels and pretask (anticipation) levels were subjected to 2 (social anxiety) x 2 (self-focus) x 2 (task periods) AN(C)OVAs with repeated measures controlling for pretask anticipation levels in case of significant correlations with delta scores. Analogue analyses were performed for changes in emotional states. As the self-focus manipulation was turned off during posttask recovery this period was not included in the analyses. Partial eta-square $\left(\eta_{\mathrm{p}}{ }^{2}\right)$ is reported as measure of effect size. Simple effects analyses and least square contrasts were performed on significant interactions involving a priori hypotheses. Tukey's post hoc comparisons were utilized for a-posteriori comparisons among means [42]. 


\section{RESULTS}

\section{Group Comparisons at Baseline}

ANOVAs revealed no main effects or interactions for baseline $\operatorname{HR}(M=74.72, S D=10.76 ; p$ 's $>0.12)$. For baseline levels in SBP $(M=114.39, S D=7.33)$ and DBP $(M=69.96, S D=5.30)$ social anxiety x self-focus interactions were observed [SBP: $F(1,56)=5.16, p=0.03, \eta_{\mathrm{p}}{ }^{2}=0.08$; DBP: $\left.F(1,56)=5.31, p=0.03, \eta_{\mathrm{p}}{ }^{2}=0.09\right]$ ]. Tukey's HSD comparisons revealed no significant differences between means, though (all $p$ 's $>0.17$ ). SBP and DBP baseline levels were unrelated to delta scores for stressor phases ( $p$ 's $>0.11$ ). Analyses of affective states at baseline revealed higher PA in low compared to high socially anxious individuals ( $M$ s 24.80 vs. 21.43 , respectively), $F(1,56)=5.35, p=0.02$, $\eta_{\mathrm{p}}^{2}=0.09$. PA baseline levels were a covariate for delta scores obtained during stressor anticipation.

\section{Cardiovascular Responses}

\section{Stressor Anticipation}

ANOVAs performed on changes from baseline $(\Delta)$ revealed a social anxiety $\mathrm{x}$ self-focus interaction for DBP reactivity $\left[F(1,56)=5.24, p=0.03, \eta_{\mathrm{p}}{ }^{2}=0.09\right]$. Analyses within each self-focus condition revealed that high compared to low socially anxious individuals experienced greater DBP reactivity in the high $(p=0.02)$ but not the low self-focus condition $(p=0.47)$, Table 1). Anticipatory DBP reactivity was related to increases in NA during stressor anticipation (semipartial $r=0.36 ; p=0.004$ ) and pre-task appraisals of demands and resources for the upcoming speaking task (demand: $r=0.38, p=0.003$; resource: $r=-0.39 ; p=0.002$ ).

Table 1. Cell means (standard deviations) for cardiovascular reactivity (changes from baseline) during stressor anticipation.

\begin{tabular}{|l|c|c|c|c|}
\hline & \multicolumn{2}{|c|}{ Social anxiety high } & \multicolumn{2}{c|}{ Social anxiety low } \\
\hline Measure & Self-focus high & Self-focus low & Self-focus high & Self-focus low \\
\hline$\Delta$ SBP $(\mathrm{mmHg})$ & $4.50(3.97)$ & $0.87(4.43)$ & $1.43(9.51)$ & $2.30(8.20)$ \\
\hline$\Delta \mathrm{DBP}(\mathrm{mmHg})$ & $4.33(5.52)$ & $0.73(3.12)$ & $-0.80(7.15)$ & $2.23(5.89)$ \\
\hline$\Delta \mathrm{HR}(\mathrm{bpm})$ & $1.97(6.12)$ & $1.07(4.88)$ & $-1.60(6.21)$ & $1.80(3.62)$ \\
\hline
\end{tabular}

Note: SBP, systolic blood pressure; DBP, diastolic blood pressure; HR, heart rate; $\mathrm{n}=15$ in each cell.

\section{Speech Preparation/Speech Performance}

$\mathrm{AN}(\mathrm{C}) \mathrm{OVAs}$ with repeated measures (social anxiety $\mathrm{x}$ self-focus $\mathrm{x}$ task periods) performed on change $(\Delta)$ scores revealed significant task main effects for $\operatorname{SBP}\left[F(1,56)=89.27, p<0.0001, \eta_{\mathrm{p}}{ }^{2}=0.62\right]$, DBP $[F(1,56)=42.73, p<$ $\left.0.0001, \eta_{\mathrm{p}}{ }^{2}=0.43\right]$, and a marginally significant effect for $\operatorname{HR}\left[F(1,55)=3.09, p=0.08, \eta_{\mathrm{p}}{ }^{2}=0.05\right]$. Speech preparation elicited significantly lower SBP ( $M \mathrm{~s} \Delta 6.62$ vs. $23.43 \mathrm{mmHg})$, DBP (Ms $\Delta 3.17 \mathrm{vs} .13 .78 \mathrm{mmHg})$, and $\mathrm{HR}$ ( $M \mathrm{~s} \Delta 8.11$ vs. $11.57 \mathrm{bpm})$ elevations compared to speech performance. The ANCOVA for HR also revealed a significant task x social anxiety interaction $\left.\left[F(1,55)=5.05, p=0.03, \eta_{\mathrm{p}}{ }^{2}=0.08\right)\right]$ that was further specified by a task $\mathrm{x}$ social anxiety x self-focus interaction $\left[F(1,55)=5.53, p=0.02, \eta_{\mathrm{p}}{ }^{2}=0.09\right]$. Simple effects analyses performed for each task separately revealed that the social anxiety x self-focus interaction was valid for speech preparation $[F(1,55)$ $\left.=8.16, p=0.006, \eta_{\mathrm{p}}{ }^{2}=0.13\right]$. Analyses within each social anxiety group observed low socially anxious individuals to display markedly greater HR elevations in the condition with enhanced self- focus compared to low self-focus ( $p=$ 0.009 , Table 2), whereas high socially anxious individuals showed no difference $(p=0.20)$. Secondary analyses within self-focus conditions revealed social anxiety effects for low $(p=0.05)$ and high self-focus conditions $(p=0.05)$ that pointed in opposite directions. Under enhanced self-focus low socially anxious individuals displayed greater reactivity, under low self-focus it was the high socially anxious group. During speech performance a social anxiety main effect was observed $\left[F(1,55)=4.84, p=0.03, \eta_{\mathrm{p}}{ }^{2}=0.08\right]$ with high socially anxious individuals displaying greater HR elevations compared to low anxious individuals ( $M \mathrm{~s} \Delta 14.42 \mathrm{vs} .8 .72 \mathrm{bpm})$. Furthermore, the ANOVA for SBP revealed a marginal self-focus main effect, indicating greater reactivity under high compared to low self-focus (Ms $\Delta 17.30$ vs. $12.75 \mathrm{mmHg}),\left[F(1,56)=3.07, p=0.09, \eta_{\mathrm{p}}{ }^{2}=0.05\right]$. Cardiovascular responses to speech performance were unrelated to number of received prompts (all $p \mathrm{~s}>0.31$ ), but socially anxious individuals received a higher number of prompts $(1.70$ vs. 0.73$), F(1,56)=7.27, p=0.009, \eta_{\mathrm{p}}{ }^{2}=0.12$. 
Table 2. Cell means (standard deviations) for cardiovascular reactivity (changes from anticipation level) during speech preparation/speech performance.

\begin{tabular}{|l|c|c|c|c|}
\hline & \multicolumn{2}{|c|}{ Social anxiety high } & \multicolumn{2}{c|}{ Social anxiety low } \\
\hline Phase & Self-focus high & Self-focus low & Self-focus high & Self-focus low \\
\hline Preparation & \multicolumn{3}{|l|}{} & \\
\hline$\Delta \mathrm{SBP}(\mathrm{mmHg})$ & $9.87(9.17)$ & $7.50(8.72)$ & $7.27(8.32)$ & $1.83(9.22)$ \\
\hline$\Delta \mathrm{DBP}(\mathrm{mmHg})$ & $0.63(6.49)$ & $3.60(5.53)$ & $5.77(12.77)$ & $2.67(7.10)$ \\
\hline$\Delta \mathrm{HR}(\mathrm{bpm})$ & $6.17(6.01)$ & $10.17(7.83)$ & $11.63(8.26)$ & $4.47(7.96)$ \\
\hline Performance & \multicolumn{4}{|c|}{} \\
\hline$\Delta \mathrm{SBP}(\mathrm{mmHg})$ & $27.37(18.57)$ & $22.50(11.20)$ & $24.70(12.48)$ & $19.17(15.80)$ \\
\hline$\Delta \mathrm{DBP}(\mathrm{mmHg})$ & $17.53(20.76)$ & $15.00(12.52)$ & $13.87(12.11)$ & $8.70(9.59)$ \\
\hline$\Delta \mathrm{HR}(\mathrm{bpm})$ & $15.10(13.81)$ & $13.73(9.37)$ & $9.27(9.52)$ & $8.17(6.62)$ \\
\hline
\end{tabular}

Note: SBP, systolic blood pressure; DBP, diastolic blood pressure; HR, heart rate; $\mathrm{n}=15$ in each cell.

\section{Emotional Responses and Appraisals}

Differential effects for emotional responses were confined to speech performance. ANCOVAs performed on change $(\Delta)$ scores found socially anxious compared to nonanxious individuals to experience greater increases in NA $(M \mathrm{~s} \Delta 4.40$ vs. 1.07$), F(1,56)=9.12, p=0.003, \eta_{\mathrm{p}}{ }^{2}=0.14$. This difference was valid for high $(5.20 \mathrm{vs} .1 .00 ; p=0.0009)$ but not low self-focus (3.60 vs. $1.13 ; p=0.12)$. Furthermore, participants exposed to enhanced self-focus displayed lower increases in PA $\left(M \mathrm{~s} \Delta 5.13\right.$ vs. 8.53), $F(1,56)=4.32, p=0.04, \eta_{\mathrm{p}}^{2}=0.07$.

Analyses of pre-task appraisals found socially anxious individuals to experience higher demand (4.27 vs. 3.00$), F$ $(1,56)=10.75, p=0.002, \eta_{\mathrm{p}}{ }^{2}=0.16$, higher difficulty $(4.57$ vs. 3.30$), F(1,56)=12.96, p=0.001, \eta_{\mathrm{p}}{ }^{2}=0.19$, and lower coping ability (3.63 vs. 4.83), $F(1,56)=14.85, p=0.0003, \eta_{\mathrm{p}}{ }^{2}=0.21$, compared to low socially anxious individuals. Differences in perceived coping ability were substantial for high (3.20 vs. 4.87; $p=0.0004)$, but not low self-focus (4.07 vs. $4.80 ; p=0.10)$.

An ANCOVA performed on speech performance appraisals (with number of received prompts as a covariate) found ratings to be less positive in socially anxious individuals $\left(21.33\right.$ vs. $\left.32.10 ; F(1,55)=18.15, p=0.0001, \eta_{\mathrm{p}}{ }^{2}=0.25\right)$ and in individuals exposed to enhanced self-focus $\left(24.87\right.$ vs. $\left.28.57 ; F(1,55)=4.76, p=0.03, \eta_{\mathrm{p}}{ }^{2}=0.08\right)$. The self-focus effect was substantial for high (18.40 vs. $24.27 ; p=0.03)$ but not low socially anxious individuals $(31.33$ vs. $32.87 ; p=$ $0.44)$.

$\mathrm{AN}(\mathrm{C}) \mathrm{OVAs}$ (number of prompts was a covariate for $\mathrm{FAQ}_{\mathrm{other}}$ ) performed on the FAQ scales revealed a significant social anxiety main effect for $\mathrm{FAQ}_{\text {self }}\left[F(1,56)=11.59, p=0.001, \eta_{\mathrm{p}}{ }^{2}=0.17\right]$, with high socially anxious individuals exhibiting greater self-focus (13.20 vs. 10.23). Considering the moderate alpha values of the FAQ, we explored differential effects in greater detail. Three items of the $\mathrm{FAQ}_{\text {self }}$ revealed greater internal attention in socially anxious compared to nonanxious individuals: "I was focusing on my level of anxiety" (Ms 2.40 vs. $1.50 ; p=0.001, \eta_{\mathrm{p}}^{2}=0.17$ ), "I was focusing on past social failures" (Ms $\left.1.90 \mathrm{vs} .1 .23 ; p=0.009, \eta_{\mathrm{p}}{ }^{2}=0.12\right)$, and "I was focusing on my internal bodily reactions" (Ms 2.30 vs. $\left.1.33 ; p=0.0004, \eta_{\mathrm{p}}{ }^{2}=0.20\right)$. For bodily reactions also a self-focus main effect was obtained indicating higher attention to bodily reactions under high self-focus (Ms 2.13 vs. $\left.1.50 ; p=0.02, \eta_{\mathrm{p}}^{2}=0.10\right)$.

\section{DISCUSSION}

The present study evaluated the moderating influence of trait social anxiety on cardiovascular effects of enhanced self-focus. In extension of previous cardiovascular research on self-awareness, effects were evaluated during active task performance and stressor anticipation. Overall, these preliminary findings indicate the importance of considering demand characteristics in evaluating differential psychophysiological effects of enhanced self-awareness.

In agreement with experimental findings on cardiovascular activity during passive stressor anticipation [27], differential effects during this stressor period were primarily observed for vascular activity (i.e., DBP). As indicated above, elevations in DBP during situations without action opportunities were found to be mediated by alpha-adrenergic pathways $[3,27]$, i.e., increases in total peripheral resistance (TPR), and may reflect differences in emotional coping with stress [28]. The correlation of DBP reactivity with increases in negative affect observed in the current study seems 
to confirm this interpretation. As expected, greater vascular reactivity in high compared to low socially anxious individuals was primarily observed under enhanced self-focus. Interestingly, this differential effect was partly due to low anxious individuals showing a decrease rather than an increase in DBP reactivity under self-focus. In this respect, it should be considered that enhanced self-focus was found to increase awareness of physiological arousal, and there is some evidence that this bodily information may facilitate negative beliefs in high but not low socially anxious individuals $[26,43]$. Low anxious individuals may attempt to divert their attention from internal fear indices and try to more firmly establish their sense of confidence [13].

In agreement with concepts on cardiovascular adjustments in active performance situations [1, 4], effects of experimental conditions during speech preparation/speech performance were confined to cardiac parameters (i.e., SBP, HR) indicating differences in task engagement. Replicating prior research $[17,44]$, cardiac activity was unrelated to affective arousal. Interestingly, differential effects of enhanced self-focus were confined to speech preparation. The observed HR effects (an inspection of means indicates a similar pattern for SBP) are largely consistent with predictions. In low socially anxious individuals, who put forth minimal effort in the standard stress paradigm (low self-focus), seeing oneself on a TV substantially increased task engagement. As the added self-focus manipulation did not influence perceived demand or task difficulty, greater effort expenditure under enhanced self-focus might be attributed to greater success importance or an increase in potential motivation [10]. In high socially anxious individuals, who were characterized by heightened energy expenditure in the standard stress paradigm (due to greater perceived demand [4]), the added self-focus manipulation seems to have induced a moderate withdrawal effect. Lower behavioral constraints of speech preparation may have been conducive to perception of internal anxiety-related information and task-irrelevant thoughts in the self-focused condition. This mental disengagement may have interfered with task-focused efforts [13].

During speech performance, no response attenuation in socially anxious individuals was observed. In this task condition, they displayed stronger elevations in HR reactivity compared to nonanxious individuals, independent of level of self-focus. Furthermore, the modest impact of self-focus on SBP responses expressed itself similarly across high and low socially anxious individuals. Both groups were characterized by increased reactivity. Among high anxious individuals heightened reactivity under self-focus was accompanied by increased negative affect and impaired selfevaluations, though. Possibly, increased task importance (induced by enhanced self-focus) may prevent effort attenuation when behavioral constraints are high, even when success expectations are modest. Withdrawal under high self-focus might be more likely in situations with less structured demands for performance (i.e., preparation of a speech). In this respect, it might be of importance that SBP elevations in active performance situations need not necessarily be pure indicators of effort mobilization. Evaluating the interactive effects of effort and controllability, Peters et al. [45] observed SBP to vary with both factors, and the largest SBP increases occurred under high effort/low control. HR reactivity was found to vary with effort, but not controllability. Furthermore, responses under high effort/high control were of a purely sympathetic-adrenal (SA) nature (i.e., increases in catecholamines), whereas high effort in situations with low control was characterized by joint activation of both SA and HPA (hypothalamic-pituitaryadrenocortical) axes (increases in catecholamines and cortisol). According to psychophysiological models, pure SA activation reflects efficient energy mobilization in support of coping with demands [46] or performance in "challenge" [47], whereas SA/HPA coactivation is considered maladaptive, indicating effort under distress. Considering that high socially anxious individuals were characterized by impaired perceived coping resources under enhanced self-focus, keeping up effort might have elicited detrimental physiological effects. However, this is speculative without neuroendocrine measures.

In discussing effects of enhanced self-focus it should be kept in mind that an effect of the experimental manipulation on self-reports of attentional focus was only observed for bodily arousal, but not other anxiety-related aspects. Body-state information was found to be of central importance for dysfunctional cognitive processes, though [43]. In this respect, it also has to be considered that the basic social threat paradigm (presence of a camera without seeing oneself) may be partially self-focusing, which might have reduced the potential for detecting specific effects of the experimental manipulation. Another aspect concerns the validity of the FAQ. According to Deiters et al. [48], the relationship with objective measures of self-focused attention tends to be moderate. Other limitations concern the generalizability of results. The study was performed with a nonclinical female population. The majority of prior research on causal effects of self-focused attention either utilized a predominantly female sample or did not attend to gender differences. However, there is some evidence that cardiovascular [10] or psychological effects [49] of selffocused attention might be stronger in women. Furthermore, some studies found differential cardiovascular effects of trait social anxiety confined to women $[19,50]$. As regards generalizability to clinical populations, available research 
suggests similar cardiovascular and psychological effects in nonclinical and clinical socially anxious individuals [51], however greater cognitive impairment might have strengthened withdrawal tendencies in a clinical population.

\section{CONCLUSION}

These preliminary data suggest that trait social anxiety might be a relevant moderator of cardiovascular self-focus effects. However, differential effects seem to be more likely during passive stressor experience (i.e., stressor anticipation) or active demands with moderate behavioral constraints. Consistent with postulations by Carver and Scheier [13], high behavioral constraints seem to facilitate task engagement and cardiac activity both in individuals with high and low success expectations. In doubtful individuals these efforts might be accompanied by maladaptive psychological processes, though.

\section{ETHICS APPROVAL AND CONSENT TO PARTICIPATE}

Not applicable.

\section{HUMAN AND ANIMAL RIGHTS}

No Animals/Humans were used for studies that are base of this research.

\section{CONSENT FOR PUBLICATION}

Not applicable.

\section{CONFLICT OF INTEREST}

The author confirms that this article content has no conflict of interest.

\section{ACKNOWLEDGEMENTS}

Declared none.

\section{REFERENCES}

[1] Obrist PA. Cardiovascular psychophysiology: A perspective. New York: Plenum 1981. [http://dx.doi.org/10.1007/978-1-4684-8491-5]

[2] Eubanks L, Wright RA, Williams BJ. Reward influence on the heart: Cardiovascular response as a function of incentive value at five levels of task demand. Motiv Emot 2002; 26: 139-52. [http://dx.doi.org/10.1023/A:1019863318803]

[3] Hartley TR, Ginsburg GP, Heffner K. Self-presentation and cardiovascular reactivity. Int J Psychophysiol 1999; $32: 75-88$. [http://dx.doi.org/10.1016/S0167-8760(99)00003-3]

[4] Wright RA. Brehm's theory of motivation as a model of effort and cardiovascular response. In: Gollwitzer PM, Bargh JA, Eds. The psychology of action: Linking cognition and motivation to behavior. New York: Guilford 1996; pp. 424-53.

[5] Light KC, Obrist PA. Task difficulty, heart rate reactivity, and cardiovascular responses to an appetitive reaction time task. Psychophysiology 1983; 20: 301-12.

[http://dx.doi.org/10.1111/j.1469-8986.1983.tb02158.x]

[6] Richter M, Gendolla GH. The heart contracts to reward: Monetary incentives and preejection period. Psychophysiology 2009 ; 46: 451-7. [http://dx.doi.org/10.1111/j.1469-8986.2009.00795.x]

[7] Lovallo WR, Wilson MF, Pincomb GA, Edwards GL, Tompkins P, Brackett DJ. Activation patterns to aversive stimulation in man: passive exposure versus effort to control. Psychophysiology 1985; 22: 283-91.

[http://dx.doi.org/10.1111/j.1469-8986.1985.tb01602.x]

[8] Brehm JW, Self EA. The intensity of motivation. Annu Rev Psychol 1989; 40: 109-31. [http://dx.doi.org/10.1146/annurev.ps.40.020189.000545]

[9] Bögels SM, Mansell W. Attention processes in the maintenance and treatment of social phobia: hypervigilance, avoidance and self-focused attention. Clin Psychol Rev 2004; 24: 827-56.

[http://dx.doi.org/10.1016/j.cpr.2004.06.005]

[10] Gendolla GH, Richter M, Silvia PJ. Self-focus and task difficulty effects on effort-related cardiovascular reactivity. Psychophysiology 2008; 45: 653-62. [http://dx.doi.org/10.1111/j.1469-8986.2008.00655.x]

[11] Silvia PJ, McCord DM, Gendolla GH. Self-focused attention, performance expectancies, and the intensity of effort: Do people try harder for harder goals? Motiv Emot 2010; 34: 363-70. 
[http://dx.doi.org/10.1007/s11031-010-9192-7]

[12] Carver CS. A cybernetic model of self-attention processes. J Pers Soc Psychol 1979; 37: 1251-81. [http://dx.doi.org/10.1037/0022-3514.37.8.1251]

[13] Carver CS, Scheier MF. On the self-regulation of behavior. Cambridge: Cambridge University Press 1998. [http://dx.doi.org/10.1017/CBO9781139174794]

[14] Panayiotou G, Vrana SR. Effect of self-focused attention on the startle reflex, heart rate, and memory performance among socially anxious and nonanxious individuals. Psychophysiology 1998; 35: 328-36. [http://dx.doi.org/10.1017/S0048577298960875]

[15] Efran JS, Korn PR. Measurement of social caution: self-appraisal, role playing, and discussion behavior. J Consult Clin Psychol 1969; 33: 78-83.

[http://dx.doi.org/10.1037/h0027356]

[16] Feldman PJ, Cohen S, Hamrick N, Lepore SJ. Psychological stress, appraisal, emotion and cardiovascular response in a public speaking task. Psychol Health 2004; 19: 353-68. [http://dx.doi.org/10.1080/0887044042000193497]

[17] Gramer M, Saria K. Effects of social anxiety and evaluative threat on cardiovascular responses to active performance situations. Biol Psychol 2007; 74: 67-74. [http://dx.doi.org/10.1016/j.biopsycho.2006.07.004]

[18] Gramer M, Schild E, Lurz E. Objective and perceived physiological arousal in trait social anxiety and post-event processing of a prepared speaking task. Pers Individ Dif 2012; 53: 980-4. [http://dx.doi.org/10.1016/j.paid.2012.07.013]

[19] Grossman P, Wilhelm FH, Kawachi I, Sparrow D. Gender differences in psychophysiological responses to speech stress among older social phobics: congruence and incongruence between self-evaluative and cardiovascular reactions. Psychosom Med 2001; 63: 765-77. [http://dx.doi.org/10.1097/00006842-200109000-00010]

[20] Turner SM, Beidel DC, Larkin KT. Situational determinants of social anxiety in clinic and nonclinic samples: Physiological and cognitive correlates. J Consult Clin Psychol 1986; 54: 523-7. [http://dx.doi.org/10.1037/0022-006X.54.4.523]

[21] Gramer M. Social anxiety and cardiovascular responses to active coping conditions. Psychol Sci 2006; 48: 39-52.

[22] Gramer M, Sprintschnik E. Social anxiety and cardiovascular responses to an evaluative speaking task: The role of stressor anticipation. Pers Individ Dif 2008; 44: 371-81. [http://dx.doi.org/10.1016/j.paid.2007.08.016]

[23] Larkin KT, Ciano-Federoff LM, Hammel D. Effects of gender of observer and fear of negative evaluation on cardiovascular reactivity to mental stress in college men. Int J Psychophysiol 1998; 29: 311-8. [http://dx.doi.org/10.1016/S0167-8760(98)00019-1]

[24] Carver CS, Scheier MF. Self-focusing effects of dispositional self-consciousness, mirror presence, and audience presence. J Pers Soc Psychol 1978; 36: 324-32.

[http://dx.doi.org/10.1037/0022-3514.36.3.324]

[25] Clark DM, Wells A. A cognitive model of social phobia. In: Heimberg RG, Liebowitz MR, Hope DA, Schneier FR, Eds. Social phobia: diagnosis, assessment and treatment. New York: Guilford 1995; pp. 69-93.

[26] Mansell W, Clark DM. How do I appear to others? Social anxiety and processing of the observable self. Behav Res Ther 1999; 37: 419-34. [http://dx.doi.org/10.1016/S0005-7967(98)00148-X]

[27] Gregg ME, James JE, Matyas TA, Thorsteinsson EB. Hemodynamic profile of stress-induced anticipation and recovery. Int J Psychophysiol 1999; 34: 147-62.

[http://dx.doi.org/10.1016/S0167-8760(99)00074-4]

[28] Heffner KL, Ginsburg GP, Hartley TR. Appraisals and impression management opportunities: person and situation influences on cardiovascular reactivity. Int J Psychophysiol 2002; 44: 165-75. [http://dx.doi.org/10.1016/S0167-8760(01)00200-8]

[29] Brosschot JF, Gerin W, Thayer JF. The perseverative cognition hypothesis: A review of worry, prolonged stress-related physiological activation, and health. J Psychosom Res 2006; 60: 113-24. [http://dx.doi.org/10.1016/j.jpsychores.2005.06.074]

[30] Hinrichsen H, Clark DM. Anticipatory processing in social anxiety: two pilot studies. J Behav Ther Exp Psychiatry 2003; $34: 205-18$. [http://dx.doi.org/10.1016/S0005-7916(03)00050-8]

[31] Vassilopoulos SP. Coping strategies and anticipatory processing in high and low socially anxious individuals. J Anxiety Disord 2008; 22: 98-107.

[http://dx.doi.org/10.1016/j.janxdis.2007.01.010]

[32] Vassilopoulos SP. Anticipatory processing plays a role in maintaining social anxiety. Anxiety Stress Coping 2005; 18: 321-32. [http://dx.doi.org/10.1080/10615800500258149] 
[33] Spurr JM, Stopa L. Self-focused attention in social phobia and social anxiety. Clin Psychol Rev 2002; 22: $947-75$. [http://dx.doi.org/10.1016/S0272-7358(02)00107-1]

[34] Lück HE. Construction of a questionnaire for the assessment of anxiety in social situations. Diagnostica 1971; 17: 53-9.

[35] O’Brien E, Waeber B, Parai G, Staessen J, Myers MG. Blood pressure measuring devices: Recommendations of the European Society of Hypertension. BMJ 2001; 322: 531-6. [http://dx.doi.org/10.1136/bmj.322.7285.531]

[36] Vormbrock F, Neuser J. Konstruktion zweier spezifischer Trait-Fragebogen zur Erfassung von Angst in sozialen Situationen (SANB und SVSS). Diagnostica 1983; 29: 165-82.

[37] Watson D, Friend R. Measurement of social-evaluative anxiety. J Consult Clin Psychol 1969; 33: 448-57. [http://dx.doi.org/10.1037/h0027806]

[38] Watson D, Clark LA, Tellegen A. Development and validation of brief measures of positive and negative affect: The PANAS scales. J Pers Soc Psychol 1988; 54: 1063-70. [http://dx.doi.org/10.1037/0022-3514.54.6.1063]

[39] Tomaka J, Blascovich J, Kelsey RM, Leitten CL. Subjective, physiological, and behavioral effects of threat and challenge appraisal. J Pers Soc Psychol 1993; 65: 248-60. [http://dx.doi.org/10.1037/0022-3514.65.2.248]

[40] Cody MW, Teachman BA. Global and local evaluations of public speaking performance in social anxiety. Behav Ther 2011; 42: 601-11. [http://dx.doi.org/10.1016/j.beth.2011.01.004]

[41] Woody SR. Effects of focus of attention on anxiety levels and social performance of individuals with social phobia. J Abnorm Psychol 1996; 105: 61-9.

[http://dx.doi.org/10.1037/0021-843X.105.1.61]

[42] Kirk RE. Experimental design: Procedures for the behavioral sciences. USA Pacific Grove: Brooks/Cole 1995.

[43] Papageorgiou C, Wells A. Effects of heart rate information on anxiety, perspective taking, and performance in high and low social-evaluative anxiety. Behav Ther 2002; 33: 181-99. [http://dx.doi.org/10.1016/S0005-7894(02)80024-7]

[44] Gendolla GH. Self-relevance of performance, task-difficulty, and task engagement assesses as cardiovascular response. Motiv Emot 1999; 23: 45-66. [http://dx.doi.org/10.1023/A:1021331501833]

[45] Peters ML, Godaert GL, Ballieux RE, et al. Cardiovascular and endocrine responses to experimental stress: effects of mental effort and controllability. Psychoneuroendocrinology 1998; 23: 1-17. [http://dx.doi.org/10.1016/S0306-4530(97)00082-6]

[46] Dienstbier RA. Arousal and physiological toughness: Implications for mental and physical health. Psychol Rev 1989; 96: 84-100. [http://dx.doi.org/10.1037/0033-295X.96.1.84]

[47] Blascovich J, Tomaka J. The biopsychosocial model of arousal regulation. Adv Exp Soc Psychol 1996; 28 : 1-51. [http://dx.doi.org/10.1016/S0065-2601(08)60235-X]

[48] Deiters DD, Stevens S, Hermann C, Gerlach AL. Internal and external attention in speech anxiety. J Behav Ther Exp Psychiatry 2013; 44: 143-9. [http://dx.doi.org/10.1016/j.jbtep.2012.09.001]

[49] Mor N, Winquist J. Self-focused attention and negative affect: A meta-analysis. Psychol Bull 2002; 128: 638-62. [http://dx.doi.org/10.1037/0033-2909.128.4.638]

[50] Shimizu M, Seery MD, Weisbuch M, Lupien SP. Trait social anxiety and physiological activation: cardiovascular threat during social interaction. Pers Soc Psychol Bull 2011; 37: 94-106. [http://dx.doi.org/10.1177/0146167210391674]

[51] Edelman RJ, Baker SR. Self-reported and actual physiological responses in social phobia. Br J Clin Psychol 2002; 41 : 1-14. [http://dx.doi.org/10.1348/014466502163732]

(C) 2017 Gramer and Frei.

This is an open access article distributed under the terms of the Creative Commons Attribution 4.0 International Public License (CC-BY 4.0), a copy of which is available at: (https://creativecommons.org/licenses/by/4.0/legalcode). This license permits unrestricted use, distribution, and reproduction in any medium, provided the original author and source are credited. 